\title{
PIZZA ENRIQUECIDA COM FIBRAS PARA PESSOAS COM DIVERTICULOSE
}

\section{PIZZA ENRICHED WTH STAPLE FIBERS FOR PEOPLE WTH DIVERTICULOSE}

\author{
FROZZA' ${ }^{1}$, .; PENTEADO ${ }^{2}$, T.P.S; CAVASSIN³, T.A.;BORGES ${ }^{3}$, J.N.;
}

\author{
${ }^{1}$ Aluna monitora do Curso de Farmácia Industrial, UFPR \\ 2 Docente da Disciplina de Tecnologia de Alimentos Dietéticos, Departamento de Famácia, Universidade Federal do Paraná; ppenteado@ufpr.br \\ ${ }^{3}$ Graduando em Farmácia Industrial, UFPR
}

\section{RESUMO}

A alimentação pobre em fibras detemina cada vez mais o aparecimento de distúrbios gastrointestinais, como a diverticulose, os quais por modificações dietéticas planejadas podem aliviar seus sintomas, comigir deficiências nutricionais e, quando possível, remeter à causa primária da patologia. Entre os alimentos processados ricos em fibras estão as farinhas, pães, biscoitos, bolos, pizzas; importantes componentes na dieta habitual da população brasileira e que podem ser adequados as necessidades de pessoas com diverticulose. Dez formulações tipo pizza foram testadas e duas selecionadas $(F)$ contendo farelos de aveia e de trigo, em proporções iguais de $9,5 \%$, (I) e farelo de aveia e farinha de trigo integral, em proporções iguais de $19,6 \%$. Na avaliação sensorial dos protótipos, mais do que $85 \%$ dos 50 provadores não treinados responderam entre bom e muito bom numa escala hedônic a de qualidade para os atributos: aspecto, sabor, maciez, umidade e teor de sal; confimando a seleção da equipe de desenvolvimento. Além das caracteństicas nutricionais dos protótipos selecionados $(45 \mathrm{~g} \%$ de carboidratos, $9,5 \mathrm{~g} \%$ de proteínas e $5,4 \mathrm{~g} \%$ de lipídios), são de "alto teor de fibras" por atenderem a legislação vigente que determina o teor mínimo de 6 gramas de fibras por $100 \mathrm{~g}$ do produto pronto para o consumo. Sob o aspecto tec nológico, em escala de desenvolvimento laboratorial, a pizza pronta para o consumo demonstrou ser viável quando observadas as diversas operações unitánias de processamento (mistura, amassamento, moldagem e assamento) e a vida de prateleira de 10 dias, sob refrigeração e sem uso de aditivos convencionais.

Palavras-chave: diverticulose, fibras, alimentos enriquecidos.

\begin{abstract}
The poorfeeding in staple fibers of the current days the appearance of gastrointestinal riots determines each time more, which for planned dietary modific ations can alleviate its symptoms, to correct deficienciese, when possible; to send the cause primary of the pathology. Divertic ulose is an anomaly of the nomal function of the intestine; its symptoms and complications can hindered and/or be alleviated by the inclusion, in the diet, of alimentary staple fibers. It enters rich processed foods in staple fibers are flours, breads, biscuits, cakes, pizzas - the important components in the habitual diet of the Brazilian population and can be one opportunity to consumer, in special, to take care of the nec essities of people with diverticulose. Ten preparations of pizza enriched with staple fiber sources were tested, two had been selected (F) brans of oats and wheat, in equal ratios of 9,5\%, and (I) bran of oats and flour of integral wheat, in equal ratios of $19,6 \%$. The sensorial evaluation of the archetypes camied through by 50 trained cloth provers, indicate that more than $85 \%$ had answered between good and very good in a scale of quality for the attributes: aspect, flavor, smooth, humidity and text of salt; in order to confirm the election of the development team. Beyond the supplied nutrients by the archetypes selected in average of $45 \mathrm{~g} \%$ of carbohydrates, 9,5 proteins $\mathrm{g} \%, 5,4 \mathrm{~g} \%$ of lipids, and of $7,2 \mathrm{~g} \%$ (f) and $6,1 \mathrm{~g} \%$ (I) of fibers; these products can be considered of hight staple fiber because the minimum legal is the of 6 grams of staple fibers for $100 \mathrm{~g}$ of the ready product for the consumption. Underthe technological aspect, in scale of laboratorial development, the ready pizza for the consumption - it demonstrated viable when to be observed the diverse unitarias operations of processing (mixture, kneading, molding and cooking) and the life of shelf of 10 days under refrigeration and without conventional additive use.

Key Words: diverticulose, enriched foods, fibers.
\end{abstract}

1 INTRODUÇÃO

A incidência de algumas doenças crônicas tem aumentado nas populações dos centros urbanos de países industrializados, em decorência do modo agro-industrial de consumo que promoveu a substituição dosalimentos natura is pelos refina dose processados. Somado a este aumento, a migração das populações rurais para oscentros urbanos causou profundas modific ações nos hábitos a limentares dos indivíduos, ganhando popularidade a 
alimentação à base de cames, cereais refinados e açúcar. Neste contexto de mudanças alimentares, a importância das fibras na alimentação tem sido evidenciada, como por estudos epidemiológicos, quando se correlacionam o seu eleva do consumo com a menor incidência de doenças crônic as degenerativas (como as cardiovasculares e o câncer de cólon) (PROTZEK, 1997; LAJ OLO et al., 2001).

Distúrbios e doenças gastrointestina is como a síndrome do cólon imitável, hémia de hiato, apendicite, divertic ulite, doença de Crohn, hemoróidas e constipação intestinal têm sido correlacionados com à ingestão de fibra alimentar na alimentação. Muitos deles envolvem problemas de motilidade, absorção e secreção que ocorrem, em alguns casos, na ausência de condições patológicasreconhecíveis. De modo que modificações dietéticas planejadas podem aliviar sintomas, comigir defic iências nutricionais e, quando possível, minimizara causa primánia da dific uldade gastrointestinal, sendo de funda mental importância o aumento de ingestão de fibra a limentar (MAHAN, 1998, LAJ OLO et al., 2001).

Entre asdoenças crônicas, a diverticulose se caracteriza porpequenas saculações ou divertículos na parede do cólon, principalmente o sigmóide cujo enfra quecimento da parede pode sercausado porsua má formação ou pelo processo de envelhecimento. Aalta pressão dentro do cólon gerada porum esforço maiorexercido pelo cólon, através dos movimentos peristálticos, para a expulsão de um bolo fecal pobre em resíduos, como nos casos de pessoas com dietas com baixos teores de fibras, favorecem o desenvolvimento de diverticulose. No entanto, as bolsas extemas uma vez formadas, não desaparecem, propiciando a ocomência de uma condição inflamatónia temporária cíclica resultante da prisão de partículas de alimentos ou materiais nestas e, com conseqüente, crescimento bacteriano. A esta condição inflamatória dá-se o nome de divertic ulite (PECKENPAUGH e POLEMAN, 1997).

A diverticulose é comum em pessoas depois dos 30 anos, sendo que cerca de $30 \%$ dos indivíduos que desenvolvem diverticulose estão acima de 50 anos, $50 \%$ deste total acima de 70 anos e 66\% destes últimos, acima da idade de 85 anos. O aumento da prevalência com a idade sugere maior acompanhamento clínico e nutricional visto que, em todos oscasosascomplicaçõese mesmo a formação de novos divertíc ulos podem ser evitados pelo aumento da ingestão de fibrasa níveis de 10 - $13 \mathrm{~g} / 1.000 \mathrm{kcal}$ (20 - $35 \mathrm{~g} / \mathrm{dia}$ ).

Uma dieta nomal e variada inclui cerca de 25 - 30\% de fibras solúveis e $70-75 \%$ de fibras insolúveis, cujas, proporçõessão recomendadasà população em geral associada ao consumo maiorde líquidos. Osefeitosesperados ao consumo de fibrase líquidosé a redução da incidência e dos sintomas de doença diverticular, em face da diminuição da pressão dentro do trato gastrointestinal (MAHAN, 1998; LAJOLO et al., 2001; http:// nutrica oc linica.nestle.com.br/publicacoes/fibrasnutricaoenteral/\#efeitos2002).

Uma das formas de incrementara dieta com fibras é a umentar o consumo de frutas, legumes, grãos e cereais integrais, obtendo-se dessa forma um consumo equilibrado de fibras solúveis e insolúveis. A outra forma envolve o uso da ciência e tecnologia de alimentos para a inclusão de fibras alimentares na dieta e em produtos comumente consumidos pela população (PECKENPAUGH e POLEMAN, 1997).

As fibras alimentares são definidas pela Portaria n. 0 41, de 14 de janeiro de 1998, da Agência Nacional de Vigilância Sanitária do Ministério da Saúde, como: “Qualquer material comestivel de origem vegetal que não seja hidrolisado pelas enzimas endógenas do trato digestivo humano, determinado segundo o método 985.29 da AOAC 15a ed. 1990 (método enzimático - gravimétrico) ou edição ma is atual". Contudo as fibras apresentam diferentes 
caracteństicas de hidrossolubilidade, viscosidade, capacidade para reterágua e para ligar minerais e moléculas orgânicas as quais podem sofrer modific adas durante o tratamento tecnológico de suas obtenções e na produção de alimentos, afetado a estrutura tridimensional das fibras e o tamanho de suas partículas. Ambas as caractenísticas, por sua vez, influenciam nas propriedades físicas e químicas das fibras assim como a passagem através do trato gastrintestinal e os seus efeitos fisiológicos (http://nutricaoclinica.nestle.com.br/ publicacoes/fibrasnutricaoenteral/\#efeitos, 2002).

Muitos efeitos fisiológic os das fibras tendem a se basearem sua hidrossolubilidade. As fibras insolúveis não são viscosas e não sofrem nenhuma ou apenas uma fementação parcial no cólon, enquanto que as fibras solúveis são, com freqüência, viscosase altamente fermentáveis. A ação fundamental destas fibras é a aceleração do trânsito intestinal. Isto se deve à extrema capacidade de retenção de água das mesmas, pois, absorvendo a água disponível, aumentam em volume distendendo a parede do cólon e facilitando a eliminação do bolo fecal (http://nutric aoclinica.nestle.com.br/publicacoes/fibrasnutric aoenteral/ \#efeitos, 2002).

Entre os benefíc ios fisiológicos das fibras insolúveis estão a redução da constipação, o aumento da massa fecal, da maciez dasfezese da freqüência da evacuação, a aceleração do trânsito intestinal, o desenvolvimento da mucosa do ileo e do cólon, a intensificação da proteção contra a infecção bacteriana entre outros (http://nutric aoclinica.nestle.com.br) publicacoes/fibrasnutricaoenteral, 2002).

As fibras solúveis (pectinas, gomas e mucilagens) apresentam caractenísticas físicoquímic as como hidrossolubilidade, fementabilidade, visc osidade e ca pacidade gelific ante. Seus efeitos fisiológic os ma is a preciáveis são o retardamento do esvaziamento gástrico e o trânsito no intestino delgado, modulação da motilidade gastrintestinal, aumento da massa, volume e maciez das fezes (efeitos brandos), redução da diaréia (absorção de água aumentada), desenvolvimento da mucosa do îleo e do cólon proporcionando energia à mucosa intestinal, diminuição do pHdo cólon, aumento da proteção contra infecção (função de barreira, imunidade), aumento da tolerância à g lic ose e diminuição dosníveis de colesterol total e de $\boldsymbol{L}$ (http://nutric a oc linica .nestle.com. br/public acoes/fibra snutric aoenteral, 2002).

Entre os produtos que se tem utilizado para a inclusão de fibras na dieta estão os a limentos panifica dos. Isto se deve principalmente, poresse tipo de alimento fazerparte da dieta habitual da população, dentre elesestá incluída a pizza, devido a este serum alimento comumente consumido pela população pelo sabor, facilidade de preparo ou de ser encontrado semipronto ou pronto. Assim a incorporação de fibras na pizza poderia ser de grande auxilio para aquelas pessoas que necessitam de uma ingestão adicional de fibras na sua alimentação principalmente, como terapêutica da divertic ulose.

Para sua forma industrial é necessánio não apenas o conhecimento de tecnologias adequadas de mistura, pré-assamento, assamento empregadas durante o preparo do produto, como também as propriedades funcionais de cada ingrediente utilizado e suas funções na estruturação do produto final para o controle das transformações que sofrem durante o preparo.

\section{METODOLOGIA}

A fomulação padrão foi obtida após o teste de várias rec eitas caseiras de pizzas, sendo avalia dos vánios aspectos como critério de seleção da massa padrão. No aspecto 
tecnológico a sua obtenção através de operações unitárias simples de pesagem, mistura, tempo de crescimento da massa relativamente curto, moldagem fácil e assamento. No aspecto sensorial, a obtenção de uma massa saborosa, com teor de sal adequado que posteriomente possibilitaria cobertura com ingredientes salgados, massa homogênea estruturalmente capaz de suportaro acréscimo de fibras, umidade adequada a garantir à massa pré-assada textura não muito seca ou com aspecto de não assada (excesso de umidade), macia e de fácil corte.

Apósvánios testesfoi definida a formulação base de massa de pizza (padrão), constituída $59,9 \mathrm{~g} \%$ de farinha de trigo comum, $6,0 \mathrm{~g} \%$ de ovos, $0,6 \mathrm{~g} \%$ de fermento biológico, $0,4 \mathrm{~g} \%$ de sal e água, foram realizadas modificaçõesnas percentagense tiposde fontes alimentares de fibras e ajustes nos teores de sal, umidade e proporção de gordura.

As formulações testes e dos protótipos de massa de pizza foram desenvolvidas, em esc ala laboratorial, seguindo o procedimento da Figura 1, sendo calc uladosa composição nutricional e valor calórico total. Quando prontas a o consumo, foram submetidas à análise sensorial pela própria equipe de desenvolvimento para a seleção das melhores e que atendessem aos parâmetros definidos ao produto a ser obtido - de uma massa saborosa, macia, úmida - acrescida de fibras solúveise insolúveis em concentração recomendada à alimentação diária ideal e do público em estudo e em concordância com a legislação de alimentos enriquecidos.

O tempo e temperatura de pré e assamento da massa de pizza foram controladose variaram de acordo com a umidade da massa e quantidade de ingredientes lipídicos adic iona dos Utilizando como parâmetros de qualidade a umidade de $13-15 \%$ de umidade ao produto pré-assado, foi estabelecido como 15 minutos o tempo necessário de préassamento e mais 5 minutos para o completo assamento.

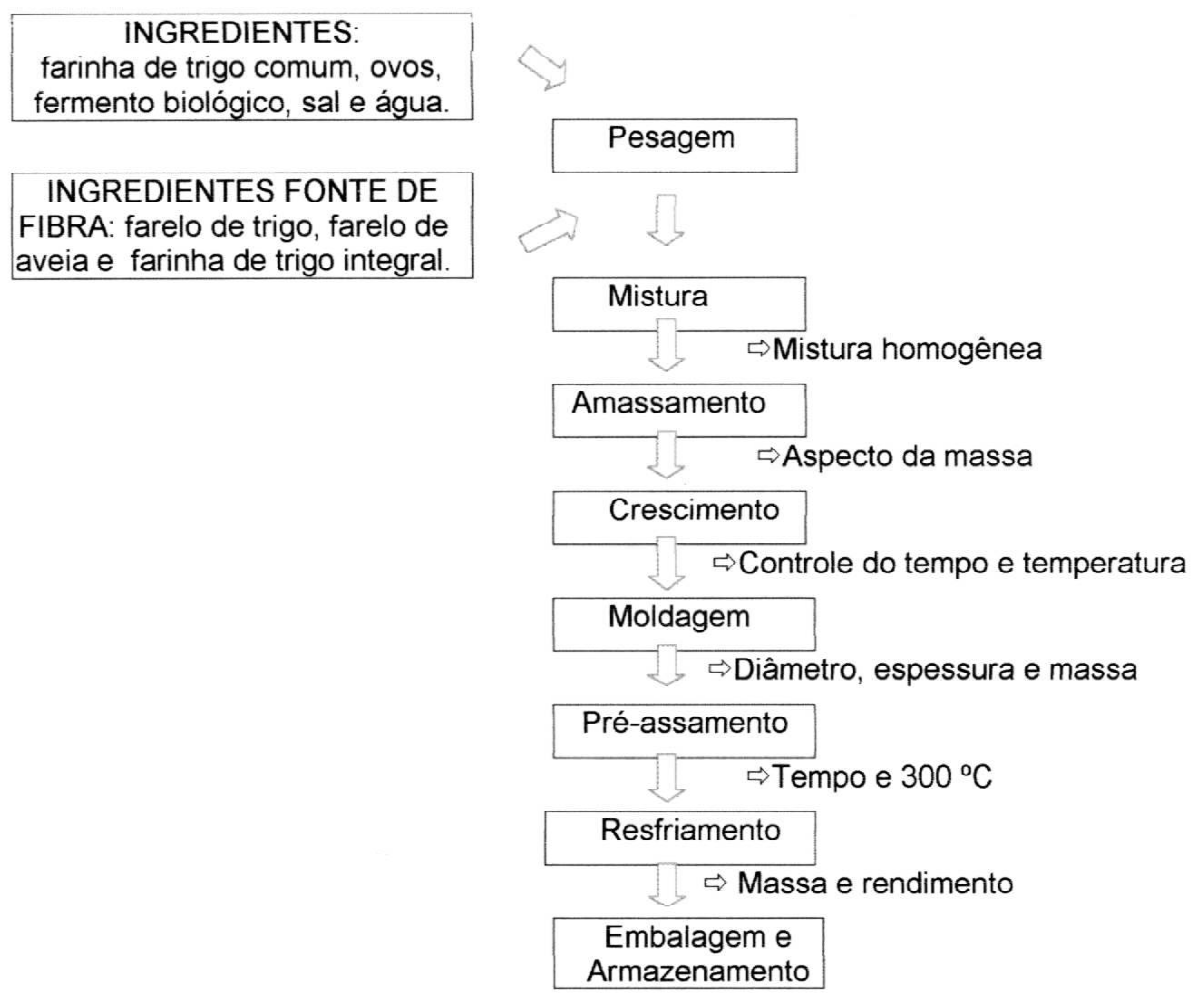

FIGURA 1 - FLUXOGRAMA DE ELABORAÇÃO DE PIZZA PRÉ ASSADA, ENRIQUECIDA COM FIBRA 
As formulações selecionadas foram submetidas, posteriomente, a ava liação sensorial por 50 provadores não treinados (consumidorem potencial); utilizando escala de hedônica dosatributos sabor, textura, cor, aspecto, maciez, teorde sale umidade confome o modelo de ficha aplicado (Quadro 2). As médias calculadas das avaliações foram plotadas em gráfico, de modo a possibilitara análise comparativa entre os protótipos.

- Para cada amostra a presentada, registre sua avaliação no quadro abaixo. Utilize os seguintes critérios de a valiação: MB (Muito Bom), B (Bom), R (Ruim), MR (Muito Ruim)

QUADRO 2 - MODELO DE FICHA PARA O TESTE DE PREFERÊNCIA DE MASSA PRÉ ASSADA, ENRIQUECIDA COM FIBRAS PARA PESSOAS COM DIVERTICULOSE

\begin{tabular}{|c|c|c|}
\hline Atributos & Y36S & Z420 \\
\hline Aspecto & & \\
\hline Maciez & & \\
\hline Textura & & \\
\hline Sabor & & \\
\hline Umidade & & \\
\hline Teorde Sal & & \\
\hline
\end{tabular}

Nota: Preferência pelo protótipo:

Comentánios e Sugestões:

\section{RESULTADOS e DISCUSSÃO}

As formulações testes e dos protótipos de massa de pizza, a presentadas na Tabela 2, foram desenvolvidasa partirdo padrão (D). A faninha de trigo foi substituída em 20 à $30 \%$ por diferentes ingredientes fontes de fibras; como o farelo de trigo, o farelo de aveia e a farinha de trigo integral, resultando em pizzas com diferentes carac teństicas sensoria is.

A formulação $E$ foi elaborada com farelo de trigo (fibra insolúvel) e com farelo de a veia (fonte de solúveis); resultando numa massa bem estruturada, porém seca, endurecida e, quando comparada ao padrão, textura maisfime e menorcrescimento da massa após o assamento. Estas caracteństicas sugeniram a necessida de de alterações na composição das gordura e água, as quais na formulação $F$ possibilitaram melhorar na formação do g lúten assim como no aspecto, na macieze na umidade da massa a póso pré-assamento e assamento; garantindo a concentração mínima de fibras recomendada pela legislação para se obter um alimento enriquecido.

TABELA 2 - FORMULAÇÕES DE MASSA DE PIZZA COM DIFERENTES FONTES DE FIBRAS (\%)

\begin{tabular}{l|c|c|c|c|c|c}
\hline \multicolumn{1}{c}{ Ingredientes (g\%) } & \multicolumn{7}{c}{ FORMULÇÕES } \\
\cline { 2 - 7 } & $\mathrm{D}$ & $\mathrm{E}$ & $\mathrm{F}$ & $\mathrm{G}$ & $\mathrm{H}$ & $\mathrm{I}$ \\
\hline Farinha de trigo comum & 59,9 & 38,4 & 38,0 & 39,9 & 19,8 & 19,8 \\
Farinha de trigo integral & - & - & - & 10,0 & 19,8 & 19,8 \\
Farelo de aveia & - & 9,6 & 9,5 & 10,0 & 19,8 & 19,8 \\
Farelo de trigo & - & 9,6 & 9,5 & - & - & - \\
Ovos & 6,0 & 5,7 & 5,7 & 6,0 & 5,9 & 5,9 \\
Fermento biológico & 0,6 & 0,6 & 0,5 & 0,6 & 0,6 & 0,6 \\
Sal & 0,4 & 0,5 & 0,5 & 0,5 & 0,5 & 0,5 \\
\hline
\end{tabular}


A formulação $\mathrm{G}$ apresentou seruma massa sensorialmente agradávelao sabor, mas com teores de fibras abaixo do especificado pela legislação; gerando a necessidade de nova formulação $(\mathrm{H})$ com modificações na proporção das fontes de fibras para cada uma delas. Contudo o aumento no teor de fibras precisou de correções quanto a proporção de gorduras na massa fomecendo maiormacieze umidade; como asrealizadas na elaboração da fomulação le na quala adição de maiorquantidade de farelo de trigo (fibras insolúveis) salientou o sabor salgado.

A Tabela 3 apresenta a composição nutricional dos protótipos selecionadose indica que as formulações $\mathrm{F} \mathrm{e} \mathrm{I}$, a inda que não tenham alterações importantes no valor calónico total mas em alguns dos nutrientes (proteína, cálc io e ferro), possuem teores de fibrassuperiores ao da massa padrão (2,2g\%). Estes protótipos atendem à Portaria 27 de 13 de janeiro de 1998 (Regulamento Técnico Referente à Informação Nutricional Complementar) referente ao enriquecimento de alimentos, visto serem alimentos prontos para o consumo e que o teor de fibras acrescido foi superior ao mínimo de 6 gramas de fibra por $100 \mathrm{~g}$ de massa sólida. Assim podem ser considerados de "alto teor de fibras" por também quando comparados a preparação pronta de pizza padrão resultam em preparações com um aumento mínimo de $25 \%$ no teor de fibras alimentares e diferença maior que $3 \mathrm{~g} / 100 \mathrm{~g}$ (sólidos).

TABELA 3 - VALOR NUTRICIONAL E CALÓRICO DA FORMULAÇÃO PADRÃO E PROTÓTIPOS DE PIZZA PRÉ - ASSADA ENRIQUECIDA COM FIBRAS

\begin{tabular}{l|c|c|c}
\hline Composição (\%) & Protótipo F & Protótipo BI & Padrão \\
\hline Carboidratos (g) & 46,0 & 45,0 & 48,0 \\
Proteínas (g) & 9,0 & 10,2 & 7,0 \\
Gorduras Totais (g) & 5,3 & 5,5 & 1,6 \\
Colesterol (mg) & 27,8 & 29,0 & 26,0 \\
Fibra alimentar (g) & 7,2 & 6,1 & 2,2 \\
Cálcio (mg) & 76,8 & 51,6 & 90,3 \\
Ferro (mg) & 2,7 & 2,3 & 1,3 \\
Sódio (mg) & 229,0 & 185,0 & 164,0 \\
Valor Calónico total (Kcal) & 244 & 244 & 247 \\
\hline
\end{tabular}

As médias das avaliações da degustação pública dos protótipos escolhidos estão representadasa Figura 3, para os atributos: aspecto, maciez, textura, sabor, umidade e teor de sal. É possível verificar que os protótipos F, H e I apresentaram médias similares e de aprovação, tendo a preferência dos degustadores para o protótipo I em especial pelo teor de sale maciez

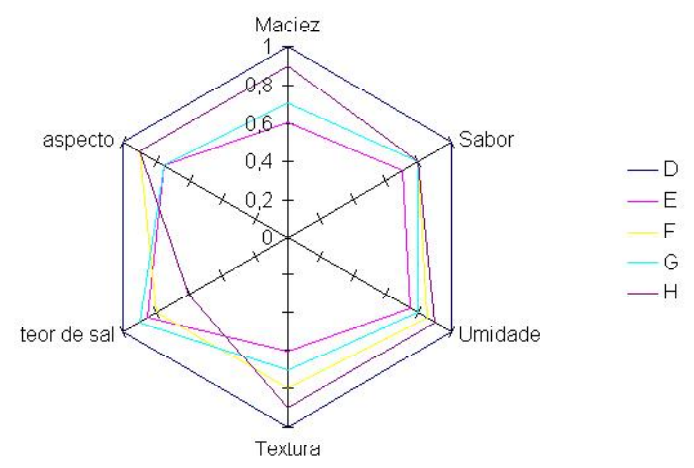

FIGURA 3 - TESTE DE PREFERÊNCIA DE PROTÓTIPOS DE MASSA DE PIZZA,ENRIQUECIDOS COM FIBRAS, PARA PESSOAS COM DIVERTICULOSE 


\section{CONCLUSÃO}

As formulações selecionadas para massa de pizza pré-assa da, enriquecida com fibras apresentaram caractenísticassenso ria is, físicase tec nológic ascompatíveis; com possibilida de de uso nutricional adequado à terapêutica da diverticulose e para consumidores de necessitem de uma ingestão adicional de fibras.

\section{REFERÊNCIAS}

1. FiBRAS Em NUIRIÇÃo enteral. Disponível em < http://nutricaoclinica.nestle.com.br/publicacoes/ fibrasnutricaoenteral> Acesso em 12 fev 2002.

2. Lajolo, F.M.; Saura-Cauxto, F.; Penna, EW.de; Meneres, E.W. de. Fibra Dietética in lberoamérica: tecnologia y salud - obtención, caracterización, efecto fisiológico y aplicación en alimentos. São Paulo: Varela, 2001. 472 p.

3. LARA, A.B.W.H.; NAZÁrJo, G.; ALMEIDA, M.E.W.de; PrEGNolATto, W. Nomas analític as do Instituto Adolfo LutZ: métodos químicos e físic os para análise de alimentos. 2.ed. São Paulo: Instituto Adolfo Lutz, 1976. v.1.

4. MAHAN, LK Krause: alimentos, nutrição e dietoterapia. São Paulo: Roca, 1998.

5. PECKENPAUGH, N.J. E POLEMAN, C.M. Nutrição: essência e dietoterapia. 7.ed. São Paulo:Roca, 1997.

6. MinistÉRNO DA SAÚdE - Agência Nacional de Vigilância Sanitária. Portaria 27 de 13 de janeiro de 1998. Disponível em <http://www.anvisa.gov.br Acesso 21 jan. 2002.

7. PROTZKK, E.C. Desenvolvimento de tecnologia para o aproveitamento de bagaço de maçã na elaboração de pães e biscoitos ricos em fibra alimentar. Curitiba, 1997. 94 p. Dissertação (mestrado em Tecnologia Química),Universidade Federal do Paraná, Cunitiba.

8. QUAGUA, G. Ciencia y tecnología de la panificacion. Zaragoza: Acribia, 1991. 